\title{
Research on the Difficulties Faced by International Education Industry and Its Solutions Under the COVID- 19 Epidemic Situation
}

\author{
Yifei $\mathrm{He}^{*}$ \\ The Affiliated High School of Fujian Normal University, Fuzhou, Fujian, 350007, China \\ *Corresponding author. Email: zf@fjsdfz.com
}

\begin{abstract}
The outbreak of COVID-19 has had a significant impact on China's economy and society. In particular, it is a huge challenge for some small, medium and micro-sized enterprises which are resistless. This article mainly studies the difficulties faced by international education industry and its solutions under the COVID-19 epidemic situation. Out of consideration for their own safety and the international situation, a large number of students give up studying abroad, which will inevitably lead to a decrease in the demand for international education market. In order to cope with the impact of COVID-19 on the international education industry, the actual situation of enterprises, the duration of the epidemic and the extent of its impact should be taken into account. On the one hand, enterprises should seek help outside the enterprises. They should focus on the latest support policies, and seek help from third-party institutions. On the other hand, they have to consider the level of enterprise development, pay attention to cash flow, actively explore the market and speed up enterprise transformation in order to make up for the loss during downtime.
\end{abstract}

Keywords: COVID-19, Small, Medium and Micro-sized Enterprises, International education industry, Solving strategy, Study abroad

\section{INTRODUCTION}

The past several years we have witnessed a gradual increase in the number of students who would study abroad after graduating from the high school, which means there is a growing tendency for Chinese families to send their kids to study abroad. They may embrace a view point that studying abroad can cultivate thinking, skills to analyze and solve problems and contribute to students' work prospects which make them more competitive in job market. It is apparent that these students will choose language training institutions to study TOEFL or IELTS, and most of them also select a study abroad agency help them to apply for the universities. Consequently, as the number of students studying abroad increase, the international education industry has good prospects for development. Contrarily, with the ravages and outbreaks of new epidemic (Corona Virus Disease 2019, COVID19), a host of Chinese families give up sending their children go abroad or they will choose gap year because of potential safety hazard, which makes some companies lose a large number of customers. What worse, the epidemic prevention and control measures implemented by governments have also bring some negative influence to some companies. It can be seen that the international education industry cannot develop as smoothly as before and they have to face great challenges.

\section{LITERATURE REVIEW}

\subsection{The Impact of COVID-19 on Enterprises}

Wang Zheng and Chen Wenhui (2020) believe that the epidemic has impacts on small, medium and micro-sized enterprises such as the weak demand of domestic consumer service market, the pressure of short-term operating costs and expenditure, and the high risk of debt such as loan breaking and loan withdrawing [1]. Liu Haifei (2020) pointed out that since the outbreak of the epidemic, most of the small, medium and micro enterprises have gradually resumed their work, but a large part of them still face huge external pressure from various aspects. The most serious of them is the fixed cost during the shutdown and this pressure is enough to make all the small, medium and micro enterprises linger on in a steadily worsening condition [2]. Wang Wanfen and Wang Zihui (2020) argues that in a short period of time, the external factors bring great influence to the micro, small and medium enterprises. These factors lead to the company's products and raw material prices float, and a host of orders were cancelled. In addition, some export trade corporations are facing the risk of a breach of contract. It can be seen that the external factors under the epidemic have a lot of negative impacts on small, medium and micro-sized enterprises [3]. 
Wang Zhen (2020) believed that the epidemic had a certain impact on the employment of small, medium and micro-sized enterprises in different industries. Because of the restriction of traveling, the business of catering service was sluggish, and some restaurants had to reduce their staffs. The volume of traffic and transportation and the demand of daily entertainment have been greatly reduced. These situations mainly concentrated in some small, medium and micro-sized enterprises with weak resistance [4]. Through a series of investigations, Huang Yejing (2020) found that the impact of the epidemic on small, medium and micro-sized enterprises was quite different in different industries, and the most severely affected was the labor-intensive service industry. There are a series of service places such as restaurants, cinemas, tourist attractions, large-scale conferences and expositions. Hence, it can be found that the COVID-19 has affected small, medium and micro-sized enterprises in different industries in different ways and to different degrees [5].

\subsection{Some Solving Strategies under the COVID-19 Epidemic Situation}

With the coordinated promotion of the national government, certain success has been achieved, but certain problems have also been exposed. Therefore, these problems need to be solved urgently. Many domestic scholars have expressed their views and put forward suggestions. Zhang Weiping (2020) proposed that financial support should be strengthened, and local governments at all levels should play a significant role in theb comprehensive coordination and the service guarantee. These are main ways to solve the major difficulties of small, medium and micro-sized enterprises [6]. Zhang Zhiyuan, Ma Yongfan and Hu Xingcun (2020) proposed the policy path of financial supply support for small, medium and micro-sized enterprises under the impact of the epidemic from three perspectives. In the short term, the government intervention should be increased, and corresponding rescue policies should be issued. In the medium term, it is necessary to follow up and ensure the guidance of various institutions for enterprises' assistance. In the long-term, we need to carry out investigation deeply and try to improve the rules and regulations [7]. Zhu Wuxiang (2020) argue that as the industry division of labor is more segmentation, small, medium and micro-sized enterprises will emerge some special industry. We should make electric business platforms as good resources, and the financial staff of the enterprise should effectively manage the bailout fund [8].

\section{THE IMPACTS OF COVID-19 ON THE INTERNATIONAL EDUCATION INDUSTRY UNDER THE PEST MODEL}

\subsection{Political Factors}

Under the COVID-19 epidemic situation, most countries will take certain measures to ensure the safety of their citizens. For example, the Ministry of Foreign Affairs and The Ministry of Culture and Tourism have issued security alerts to remind citizens to travel to some high-risk areas. At the same time, the state has restricted the entry of citizens from some other countries, which greatly reduces the flow of people from different countries. For some international schools or language training institutions, some foreign instructors may not be able to return to work smoothly, which affects the course arrangements. Although some foreign instructors have taught online, there is still a gap between them and students. Some students and parents believe that it greatly affects the quality of the course. A host of students who have studied abroad will come back to study TOEFL or IELTS in summer and winter vacation, and some of them take part in programs of scientific research in order to increase its soft power background. However, under different policies in different countries, returning is also more difficult for students, and there is no denying the fact that it brings some negative effects to language training institutions.

From the perspective of students and parents, they always feel a little worried when they see the official announcement or the policy issued by the state so that they may give up choosing to study abroad and turn to take part in National College Entrance Examination in China. This has led some international educational institutions to default on refunds.

\subsection{Economic Factors}

Prior to the COVID-19 outbreak, the number of students studying abroad increased over the years, which leads to increased demand for language training and study abroad agents. Hence, the competition between companies in education industry is also drastic, because one student can be serviced more than one projects, and it will make each education companies more cherish to each student. After outbreak of the COVID-19, the sales of absolute part of the company is declining, some agencies will intensify their preferential strategies, appeared "discount" to attract parents and student to sign up and pay tuition. Such a "price war" will have an impact on every company in the industry.

From the perspective of students' parents, some parents their own companies have been hit by COVID-19. Due to the shutdown, a large number of enterprises have to reduce costs and parents' income has been greatly reduced. Studying abroad requires a huge amount of money, which is a huge burden for parents. Some students who have 
prepared for studying abroad for a long time may be forced to give up studying abroad due to insufficient funds in their family. This leads to some students take part in the National College Entrance Examination in China instead of continuing learning foreign language, which will naturally reduce the number of students.

\subsection{Social and Cultural Factors}

In the past, students might wait for graduating from university and go abroad for graduate study. With the development of the times, there is a growing tendency for younger children to study abroad, which means families choose to send their children abroad after graduation from junior high school or senior high school. With the outbreak of COVID-19 in western countries, these young people are living alone, and the parents will inevitably be worried about the safety of their children. Thus, those families which plan to let their kids go to America for high school or undergraduate will perish the thought of sending children study abroad immediately.

Faced with the ravages of COVID-19 in the West and strained relations between China and other parts of the West, many relatives will persuade parents to let children stay in China instead of sending them abroad. When students' parents see the social unrest in foreign countries and some phenomenon of Exclusive-Chinese in some regions, they will be afraid of sending their young children to study abroad. Influenced by the international situation, it is true that a majority of students will give up going abroad.

Moreover, in recent years, the number of Chinese students applying for undergraduate study in the United States has been increasing year by year, and the pressure of studying abroad competition is also increasing, which even approach the pressure of domestic college entrance examination. What's worse, with the outbreak of COVID19 , the road to study abroad has become more difficult.

\subsection{Technological Factors}

With the progress and development of technology, online office software like Zoom and Ding Talk. In many language training, study abroad agency and some other international education companies began to work or teach online. Although this help students teachers not to leave home, enterprise needs to pay a certain time and money to train teachers to learn how to use these online office software. What' worse, a lot of activity is confined to faceto-face communication. Without face-to-face interaction, students' enthusiasm is relatively low, which means efficiency of online teaching is low. Hence, online teaching has a great influence on the quality of teaching.

Due to the popularity of online teaching, some parents of students start to choose some institutions out of the city they live in. They can communicate with local institutions face to face when they find that the epidemic has not occurred. Even so, after the outbreak of the epidemic, local institutions can only communicate through Internet, which is not much different from the institutions in other city.

\section{ANALYSIS OF THE IMPACTS OF COVID-19 ON THE INTERNATIONAL EDUCATION INDUSTRY BASED ON QUESTIONNAIRE SURVEY}

\subsection{Questionnaire Design and Descriptive Statistics}

In September 2020, we had a questionnaire survey on the impact of COVID-19 on the difficulties faced by international education industry and its solutions under the COVID-19 epidemic situation. There are twenty-two questionnaires were received. The survey included eight questions, including the background of the company, the situation affected by the epidemic, the measures taken and the future prospects of the industry. The survey method uses specialized network information platform and adopts the form of on-line questionnaires. As shown in Figure 1, those with 5 10 employees account for $13.64 \%$, those with 11 15 employees account for $9.09 \%$, those with 20 or more employees account for $77.27 \%$. As shown in Figure 2 , the main service object of preschool children's business accounted for $4.55 \%$, the main service object covers the elementary student's enterprises accounted for $9.09 \%$, the main service object of the junior middle school students business accounted for $31.82 \%$, the main service object of high school students business accounted for $90.91 \%$, the main service object of undergraduate business accounted for $90.91 \%$, the main service object graduate business accounted for $59.09 \%$, the main service object of doctoral student business accounted for $13.64 \%$.

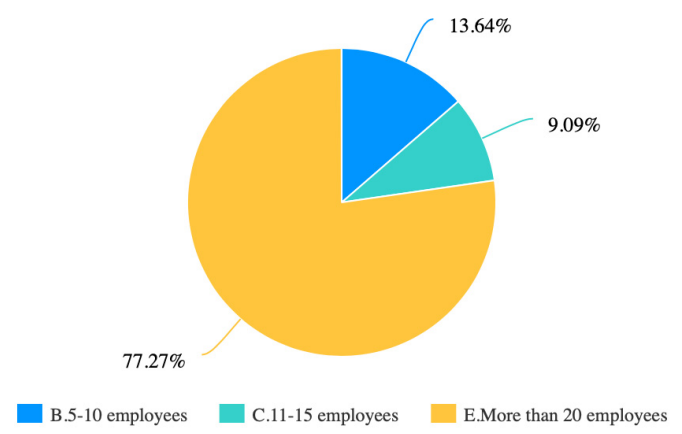

Figure 1 The number of the employees 


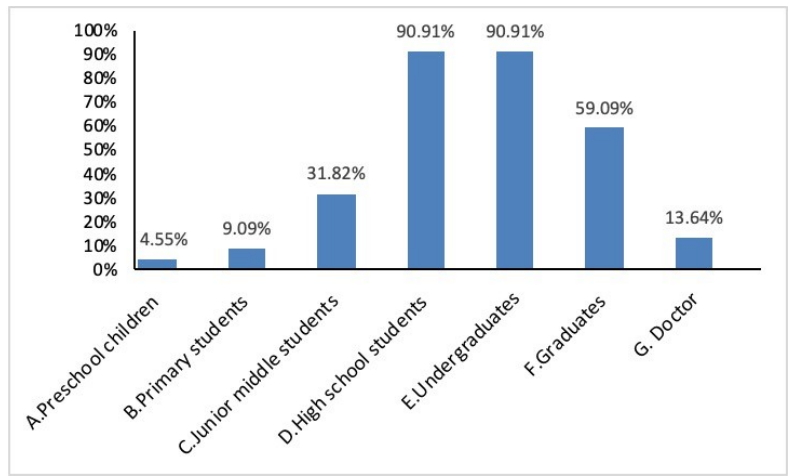

Figure 2 Main Service Target

\subsection{Analysis of the Difficulties Faced by International Education Industry}

As shown in Figure 3,there are 63.64\% enterprises found that compared with before the outbreak, the market demand is greatly reduced, $4.55 \%$ enterprises had a financial institution loans and take out loans, enterprises with some important employee retention accounted for $31.82 \%$, the enterprises with the large pressure of the short-term operating cost accounted for $18.18 \%$, the enterprises with the situation of canceling the contract, faced with the risk of a breach of contract accounted for $45.45 \%$, enterprises which think that other enterprises in the industry reduce tuition fees and leads to a "price war" accounted for $59.09 \%$, the enterprises which think that some companies in the industry will go out of business, leads to less competitors accounted for $40.91 \%$, the enterprises which believe that the government had introduced some favorable policies which play a role in corporate development accounted for $9.09 \%$.

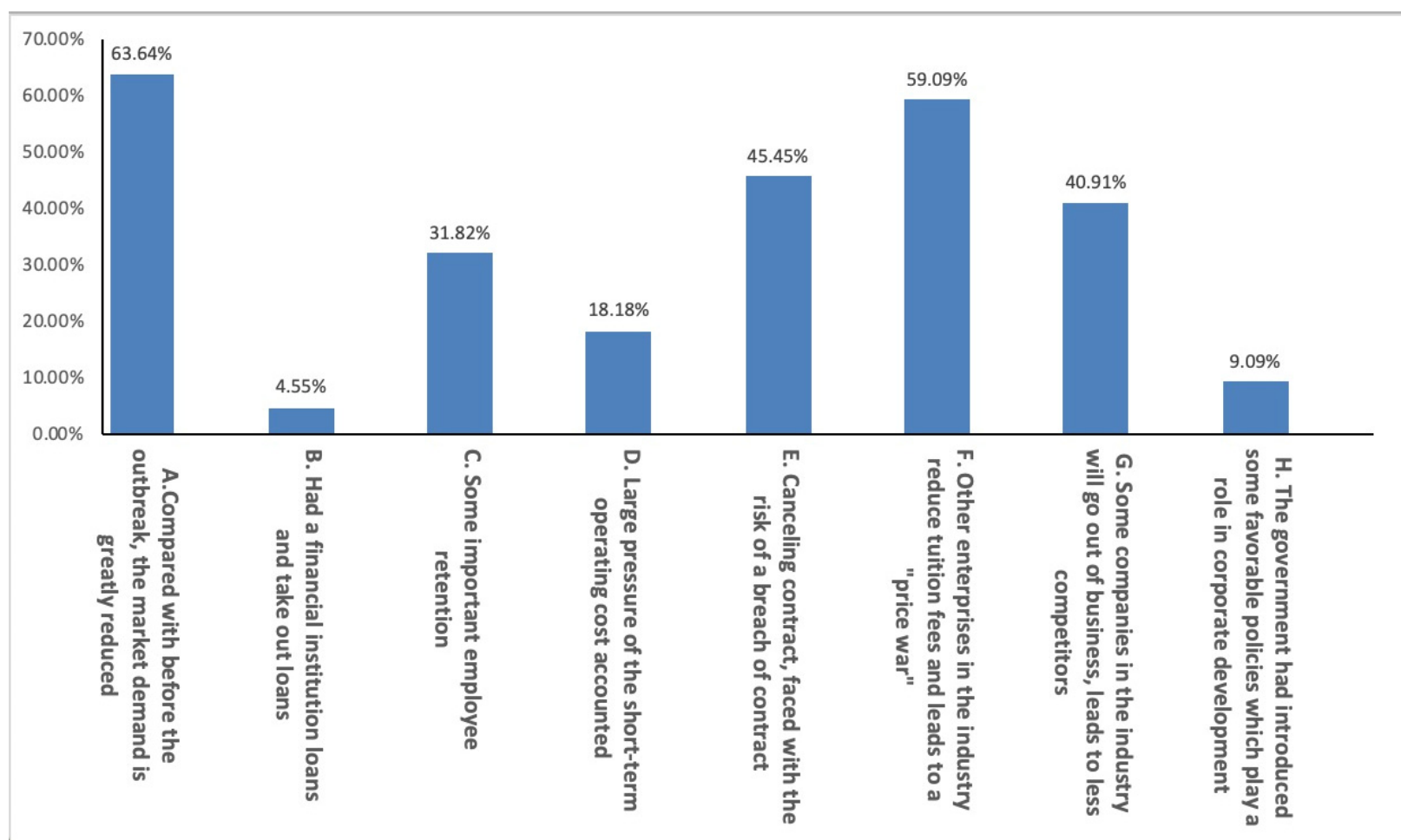

Figure 3 The difficulties faced by international education industry

First of all, a large number of enterprises feel that the outbreak of COVID-19 has greatly reduced the market demand. This is because many families will let children who have chose to study abroad study in China instead of going abroad out of concern for their lives and safety, which definitely reduce the number of children who choose to study abroad. Secondly, increasing industry competition is an important problem encountered by most enterprises. In order to relieve the pressure of the cash flow, many enterprises need a large amount of cash to ensure the normal operation of the company. In order to obtain cash in a short time, most enterprises will choose to lower tuition fees to attract more parents and students to sign up for payment. What' more, some students who have already signed up, fearing that it will be more difficult to go abroad in the future, will choose to take the college entrance examination instead of studying abroad. This leads the enterprises have the situation of canceling the contract, faced with the risk of a breach of contract. 


\subsection{Solutions of the Difficulties under the COVID-19 Epidemic Situation}

Moreover, all of the companies in the education industry will take some measures to save themselves. As shown in Figure 4 , There are $13.64 \%$ of the enterprises have joined the International Education Industry Alliance \& Association to work together with other institutions to overcome the difficulties, $4.55 \%$ of the enterprises have borrowed from some financial institutions according to the latest policy , $54.55 \%$ of enterprises reduce cost, $54.55 \%$ of enterprises transformation to develop other businesses,
$59.09 \%$ of enterprises use online video conferencing software to carry out online education, $86.36 \%$ of the enterprises to develop new marketing plan to increase the competitive in the industry, there are $63.64 \%$ of the enterprises perfect online teaching way to guarantee the students' learning efficiency during the outbreak, $31.82 \%$ of companies make the employee welfare policy, retain key employees, $63.64 \%$ of enterprises share the latest overseas study information on public accounts, online platforms or offline lectures to reduce the anxiety of students and parents about studying abroad.

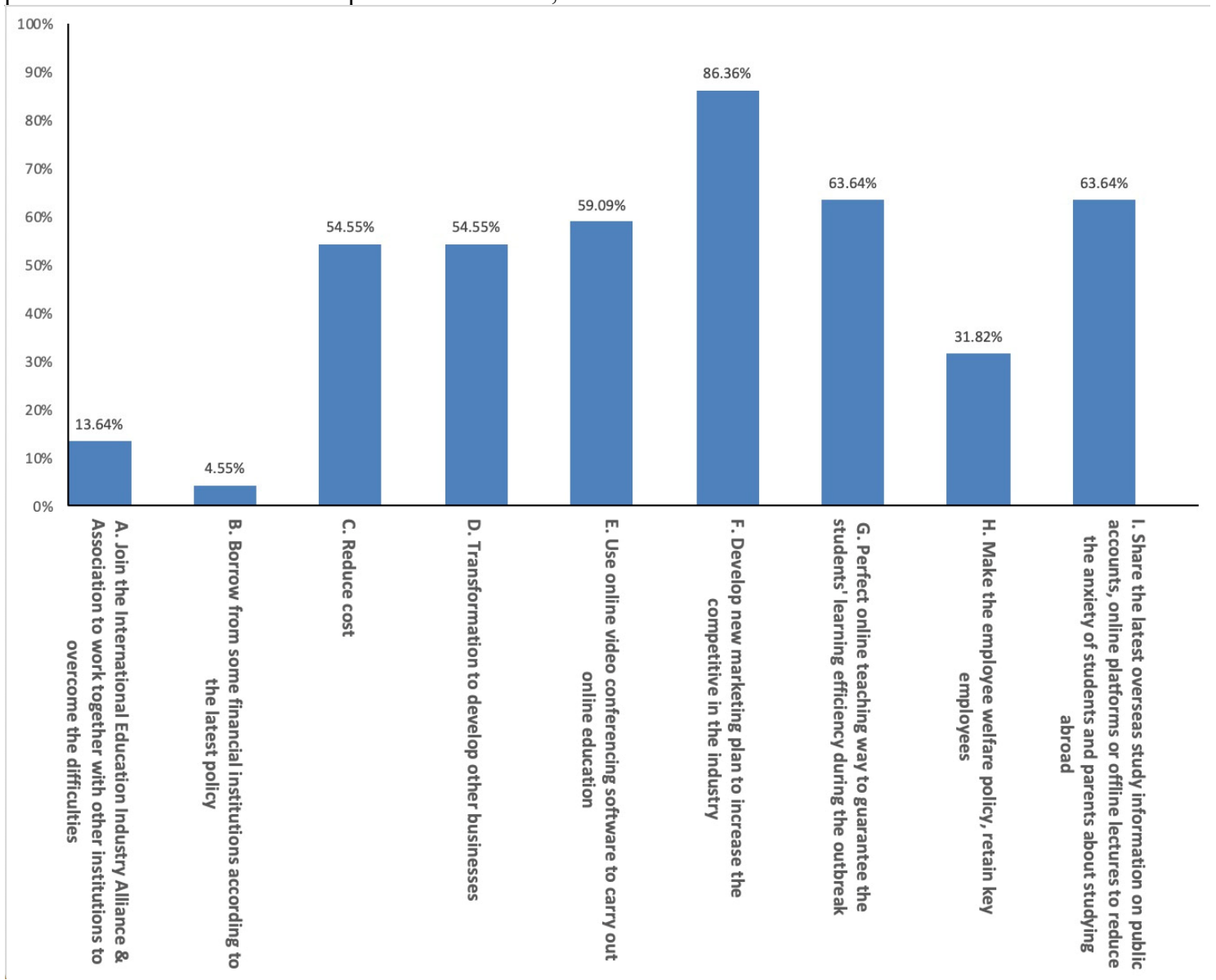

Figure 4 Solutions of the difficulties under the COVID-19 epidemic situation

A considerable number of enterprises will develop new marketing programs to increase their competitiveness in the industry. This is because they all feel that the COVID19 is bringing more and more competitive pressure to the industry. If they want to survive, they must increase their competitiveness in the industry. Few enterprises will seek help from a third party, and it can be found that the enterprises in the industry only find problems and its solutions within their own companies and ignore help outside the enterprise. However, small, medium and micro-sized enterprises are relatively weak in working capital, human resources and business capabilities. Compared with those large enterprises, their anti-risk capabilities are significantly lower.

\subsection{Implementation of Existing Policies and Attitude of Industry's Prospect}

In addition, there are $36.36 \%$ of enterprises hold the view point that administrative department, financial institutions basically solved the main problems, and there has almost no problem in the implementation strategy, $45.45 \%$ of companies claim that administrative department, financial institutions solve only a part of the difficulty, there are still some problems in the implementation of the strategy, there are $18.18 \%$ of enterprises harbor an idea that only solve a 
few difficult or basic no problem, there are still more problems in the implementation of the strategy.

As shown in Figure 5, of future prospects of the industry, $72.73 \%$ of enterprises believe that at this stage has met certain blow, but will soon be back to normal, and outlook is still good. There are 27.27 companies feel blow at the present stage is larger, inside and outside the joint effort, and they can barely survive. No firm think blow is too big, at present stage enterprise hard to survive, and the outlook is dark.

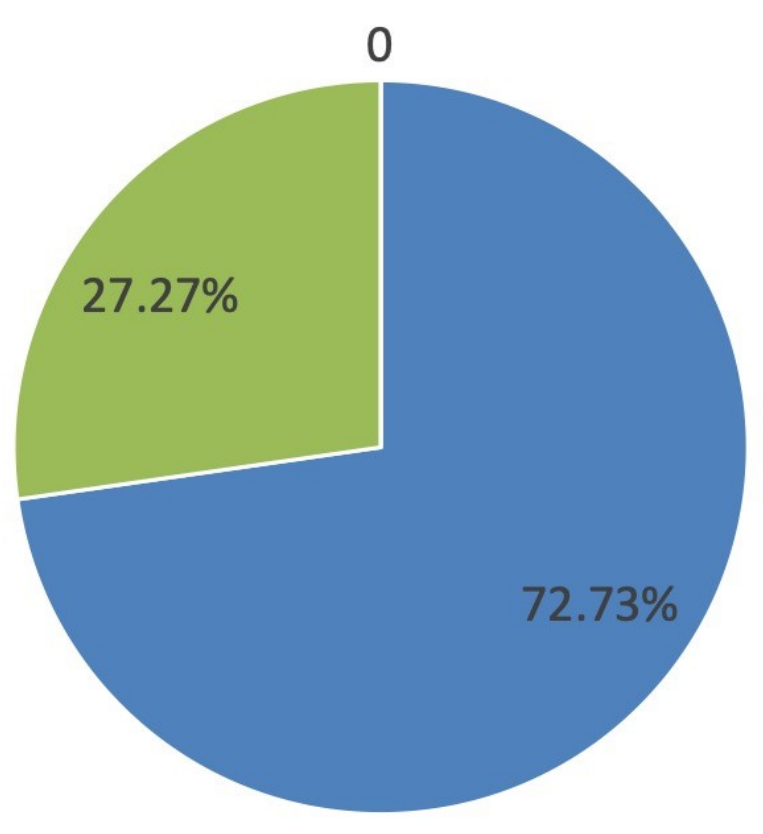

- A. At th is stage has met certain blow, but will soon be back to normal, and outlook is still good

$=$ B. Blow at the present stage is larger, inside and outside the joint effort, and they can barely survive

- C. Blow is too big, at present stage enterprise hard to survive, and the outlook is dark

Figure 5 Future prospects of the industry

\section{CONCLUSION AND RECOMMENDATION}

\subsection{Conclusion}

The epidemic has had a significant impact on the international education industry, and these small-scale enterprises have been more negatively affected. Due to the long incubation period, high infectibility and uncertain duration of COVID-19, students became more fearful of the epidemic and gave up studying abroad, which greatly reduced the market demand. In fact, the international education industry was under great cash flow pressure to maintain and resume operations during the epidemic period, but the enterprises themselves did not find that these enterprises were mostly seeking problems within their own enterprises and ignoring external support. In fact, after some government policies, these enterprises still need to actively seek financial support to tide over the difficulties of survival and resume business.

\subsection{Recommendation}

Since the outbreak of COVID-19, many enterprises have responded in the first place. Most companies look at the industry and focus on their own internal problems to solve them. Very few companies turn to outside agencies for help. In fact, in order to better tide over the difficulties, these enterprises should attach importance to the help of the third party institutions, find ways to make good use of these institutions, with their help to alleviate their own problems, rather than blindly bravado, relying on their own strength to solve the problems. These companies can join the International Education\&Industry Association, work with other institutions to tide them over or borrow money from financial institutions in accordance with the latest policy.

\section{REFERENCES}

[1] Z. Wang.W.H. Chen. Post-epidemic period: Further rescue strategies for Micro, small and medium-sized 
enterprises in China $[\mathrm{J}]$. 《 Price:Theory \& Practice》,2020(04):319-322.

[2] H.F. Liu. Short-term Countermeasures of Small, medium and micro enterprises in Guangdong during the post-epidemic period[J]. Modern Business Trade Industry,2020(14):5-6.

[3] W.F. Wang, Z.W. Wang. Investigation on the production, operation and financing of small and micro enterprises under the COVID-19 epidemic[J]. Jiangnan Forum,2020(04):23-25.

[4] Z. Wang. Impact of COVID - 19 on China's Employment Protection and Social Security System[J]. Economic Review Journal,2020(03):7-15.

[5] Huang Yejing.Challenge to SMEs Survival and Operation under COVID-19 Breakout----- Impact, Determinants and Countermeasures[J]. Shanghai Economy,2020(02):21-28.

[6] Z. Y. Zhang, Y. F. Ma, X. C. Hu. Research on Financial Supply Support for Small and Medium-Sized Enterprises under the Impact of the Epidemic[J]. Public Finance Research, 2020(04):58-65.

[7] L. Xu, P. X. Fu, L. Zhu. Analysis of supporting policies on the impact of COVID-19 on smes[J].China Small \& Medium Enterprises,2020(03):22-27.

[8] W. X. Zhu, P. Zhang, P. F. Li, et al. Firm Crisis, Government Support and Policy Efficiency under the Epidemic Shock: Evidence from Two Waves of Questionnaire on SMEs[J]. 《 Management World》,2020(04):13-25. 